\title{
Spontaneous ketonuria and risk of incident diabetes: a 12 year prospective study
}

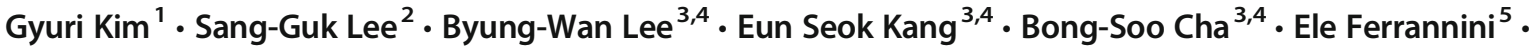 \\ Yong-ho Lee Le, $^{3,6}$ Nam H. Cho ${ }^{7}$
}

Received: 11 October 2018 / Accepted: 14 January 2019 / Published online: 20 February 2019

(C) Springer-Verlag GmbH Germany, part of Springer Nature 2019

\begin{abstract}
Aims/hypothesis Ketones may be regarded as a thrifty fuel for peripheral tissues, but their clinical prognostic significance remains unclear. We investigated the association between spontaneous fasting ketonuria and incident diabetes in conjunction with changes in metabolic variables in a large population-based observational study.

Methods We analysed 8703 individuals free of diabetes at baseline enrolled in the Korean Genome and Epidemiology Study, a community-based 12 year prospective study. Individuals with $(n=195)$ or without fasting ketonuria were matched 1:4 by propensity score. Incident diabetes was defined as fasting plasma glucose $\geq 7.0 \mathrm{mmol} / \mathrm{l}$, post-load $2 \mathrm{~h}$ glucose $\geq 11.1 \mathrm{mmol} / 1$ on biennial OGTTs, or current use of glucose-lowering medication. Using Cox regression models, HRs for developing diabetes associated with the presence of ketonuria at baseline were analysed.

Results Over 12 years, of the 925 participants in the propensity score-matched cohort, 190 (20.5\%) developed diabetes. The incidence rate of diabetes was significantly lower in participants with spontaneous ketonuria compared with those without ketonuria (HR 0.63; 95\% CI 0.41, 0.97). Results were virtually identical when participants with fasting ketonuria were compared against all participants without ketonuria (after multivariate adjustment, HR 0.66; 95\% CI 0.45, 0.96). During follow-up, participants with baseline ketonuria maintained lower post-load $1 \mathrm{~h}$ and $2 \mathrm{~h}$ glucose levels and a higher insulinogenic index despite comparable baseline values.

Conclusions/interpretation The presence of spontaneous fasting ketonuria was significantly associated with a reduced risk of diabetes, independently of metabolic variables. Our findings suggest that spontaneous fasting ketonuria may have a potential preventive role in the development of diabetes.
\end{abstract}

Keywords Cohort $\cdot$ Diabetes $\cdot$ Ketone $\cdot$ Risk

Electronic supplementary material The online version of this article (https://doi.org/10.1007/s00125-019-4829-x) contains peer-reviewed but unedited supplementary material, which is available to authorised users.

Yong-ho Lee

yholee@yuhs.ac

$\triangle$ Nam H. Cho

chnaha@ajou.ac.kr

1 Department of Medicine, Samsung Medical Center, Sungkyunkwan University School of Medicine, Seoul, Republic of Korea

2 Department of Laboratory Medicine, Yonsei University College of Medicine, Seoul, Republic of Korea

3 Department of Internal Medicine, Yonsei University College of Medicine, 50-1 Yonsei-ro, Seodaemun-gu, Seoul 03722, Republic of Korea
4 Institute of Endocrine Research, Yonsei University College of Medicine, Seoul, Republic of Korea

5 CNR Institute of Clinical Physiology, Pisa, Italy

6 Department of Systems Biology, Glycosylation Network Research Center, Yonsei University, Seoul, Republic of Korea

7 Department of Preventive Medicine, Ajou University School of Medicine, 164 World cup-ro, Yeongtong-gu, Suwon 16499, Republic of Korea 


\section{Research in context}

\section{What is already known about this subject?}

- Ketones are regarded as a thrifty fuel for peripheral tissues; modest increments in ketone bodies may have a favourable effect on energy metabolism and signalling. However, the clinical and prognostic implications of mild fasting hyperketonaemia in healthy adults are poorly characterised

\section{What is the key question?}

- What is the relationship between the presence of spontaneous fasting ketonuria and the development of type 2 diabetes in conjunction with changes in metabolic variables?

\section{What are the new findings?}

- Ketonuria, as detected by clinical-grade strips in the morning after an overnight fast, was present in a small percentage (2.2\%) of a non-diabetic, population-based cohort

- During 12 years of follow-up, individuals with ketonuria at baseline maintained lower post-load $1 \mathrm{~h}$ and $2 \mathrm{~h}$ glucose levels and a higher insulinogenic index than those without baseline ketonuria, despite comparable baseline values

- Healthy individuals with spontaneous fasting ketonuria had a significantly lower risk of incident diabetes compared with those without ketonuria, independently of metabolic variables

\section{How might this impact on clinical practice in the foreseeable future?}

- Spontaneous fasting ketonuria may be a novel signature in the modulation of glucose metabolism and may have the potential to prevent diabetes

\section{Abbreviations}

$\beta \mathrm{HB}$

FGF21 Fibroblast growth factor 21

HMGCS2 3-Hydroxy-3-methylglutaryl-CoA synthase 2

IGI Insulinogenic index

KoGES Korean Genome and Epidemiology Study

$\operatorname{PPAR} \alpha \quad$ Peroxisome proliferator-activated receptor, alpha

SGLT2 Sodium-glucose cotransporter 2

\section{Introduction}

People with type 2 diabetes show a variety of metabolic derangements clustered around insulin resistance, pancreatic beta cell dysfunction and systemic inflammation $[1,2]$. In particular, resistance to insulin's inhibitory action on lipolysis results in increased flux of NEFA from adipose depots to all tissues. In the liver, excess delivery and oxidation of fatty substrates stimulates ketogenesis [3], thereby limiting dietinduced fatty liver injury [4]. Ketones are transported to extrahepatic tissues, where they are taken up by monocarboxylate transporters 1 and 2 [5] and readily oxidised. Because of their favourable energetics, ketones are regarded as a thrifty fuel for organs including the heart, brain and kidneys [6-8].

Ketone bodies, mostly $\beta$-hydroxybutyrate $(\beta \mathrm{HB})$, circulate at higher concentrations in individuals with diabetes as a metabolic signature of enhanced lipolysis and whole-body fat oxidation [9]. Fasting $\beta \mathrm{HB}$ levels, however, rarely exceed $1 \mathrm{mmol} / \mathrm{l}$ outside extraordinary circumstances (prolonged fasting, concomitant ketogenic diets or energy restriction, insulin omission, etc.). In non-diabetic Korean individuals, those with fasting ketonuria had a lower prevalence of obesity and the metabolic syndrome compared with those without ketonuria [10]. However, the clinical and prognostic significance of mild ketosis, as reflected by the detection of ketonuria, is still uncertain. Given the potentially beneficial role of modest increments in serum ketone bodies in energy metabolism and signalling [11], we investigated the relationship between the presence of spontaneous fasting ketonuria and the development of diabetes in a large population-based 12 year longitudinal study.

\section{Methods}

Study population The study population comprised participants in the ongoing Korean Genome and Epidemiology Study (KoGES), a prospective, community-based survey launched in 2001 by the Korean Center for Disease Control and Prevention [12]. KoGES enrolled 10,030 participants, aged 40-69 years, and includes the results of biennial health examinations and self-reported questionnaires regarding personal and family medical history, smoking and alcohol consumption, and exercise habits. For the present analysis, we excluded current steroid users $(n=15)$, people with previously diagnosed diabetes and those taking any oral hypoglycaemic agents or insulin $(n=682)$, people who had missing results 
from a $75 \mathrm{~g}$ OGTT $(n=45)$ and people with a plasma glucose concentration $\geq 7.0 \mathrm{mmol} / 1$ after an overnight fast or $\geq 11.1 \mathrm{mmol} / 12 \mathrm{~h}$ after glucose ingestion $(n=553)$ (electronic supplementary material [ESM] Fig. 1). Of the remaining 8735 individuals, 31 who had missing data of urinary ketones and one with $3+$ ketonuria test strip results - who might have had an abnormal physiological condition-were also excluded, leaving data on 8703 individuals available for analysis.

In addition, to explore the relationship between urinary ketones and serum $\beta \mathrm{HB}$ levels we retrospectively collected urinalysis data and serum $\beta \mathrm{HB}$ levels from individuals with type 2 diabetes treated with sodium-glucose cotransporter 2 (SGLT2) inhibitors $(n=441)$ at the Severance Hospital, a university-affiliated tertiary care hospital in Seoul, owing to lack of data of serum $\beta \mathrm{HB}$ in the KoGES database. All participants provided informed consent and the study protocol was approved by the Korean Center for Disease Control and Prevention and the Institutional Review Board of the Severance Hospital (IRB no. 4-2017-0287) in conformity with the Declaration of Helsinki.

Data and measurements Participants are examined every 2 years and complete self-reported questionnaires [13]. Smoking consumption was categorised as never, past smoker or current smoker, and alcohol consumption as none, $<1,1-<5$ or $\geq 5$ drinks per day, respectively. Exercise status was categorised as none or one or more times a week. Dietary assessment was performed at the baseline examination by welltrained interviewers using a 103 item semi-quantitative food frequency questionnaire; total energy intake and amounts and percentages of macronutrients, including carbohydrate, protein and fat, were estimated from the food frequency questionnaire [14-16]. The questionnaire was developed to assess the usual dietary intake of Korean adults; its validity and reproducibility were examined for the KoGES in previous reports $[17,18]$. Height, body weight and waist circumference were measured and BMI was calculated; obesity was defined as a BMI $\geq 25 \mathrm{~kg} /$ $\mathrm{m}^{2}$, according to the criteria of the WHO Asia Pacific region [19]. Total body fat-free mass $(\mathrm{kg})$ and body fat mass $(\mathrm{kg})$ were assessed by multifrequency bioelectrical impedance analysis (InBody 3.0; Biospace, Seoul, Republic of Korea). BP was measured three times in the morning after at least $10 \mathrm{~min}$ in the sitting position. Hypertension was diagnosed in participants taking antihypertensive medication or with $\mathrm{BP} \geq 140 / 90 \mathrm{mmHg}$. Blood and urine samples were obtained after at least an $8 \mathrm{~h}$ fast. Plasma total cholesterol, triacylglycerol and HDL-cholesterol were measured using a 747 chemistry analyser (Hitachi, Tokyo, Japan). LDL-cholesterol was calculated using the Friedewald equation [20]. Plasma glucose and insulin levels, sampled at $0 \mathrm{~min}, 60 \mathrm{~min}$ and $120 \mathrm{~min}$ during the OGTT, were measured using the hexokinase method and radioimmunoassay (LINCO kit; St Charles, MO, USA), respectively. $\mathrm{HbA}_{1 \mathrm{c}}$ was determined by HPLC (Variant II; Bio-Rad Laboratories,
Hercules, CA, USA). Fresh urine samples collected in the morning after the first voiding were analysed by physicians using URISCAN Pro II (YD Diagnostics, Seoul, Republic of Korea). Ketonuria results were categorised as absent, trace $(50 \mathrm{mg} / \mathrm{l}), 1+(150 \mathrm{mg} / \mathrm{l}), 2+(400 \mathrm{mg} / \mathrm{l})$ or $3+(800 \mathrm{mg} / \mathrm{l})$ based on a colour scale [10]. For the present analysis, the presence of ketonuria was defined as higher than trace level (including trace, $1+$ or $2+$ ) but did not include $3+$ test strip results. For the analysis of the relationship between strip-based ketonuria and serum $\beta \mathrm{HB}$ levels, urine samples were collected in the morning and analysed using URISCAN Pro II (YD Diagnostics). Serum $\beta$ HB levels were determined using an enzymatic immunoassay kit (Nittobo Medical, Tokyo, Japan).

HOMA-IR was calculated and insulin resistance was defined as HOMA-IR > 2.5 [21]. The insulinogenic index (IGI) was determined by plasma insulin and glucose levels at $0 \mathrm{~min}$ and $60 \mathrm{~min}$ of OGTT [22]. Incident diabetes was defined as current use of oral glucose-lowering medication or insulin, a fasting glucose level $\geq 7.0 \mathrm{mmol} / \mathrm{l}$, or a $2 \mathrm{~h}$ glucose level $\geq 11.1 \mathrm{mmol} / \mathrm{l}$ on the biennial OGTT, based on the 1997 ADA criteria [23]. The metabolic syndrome was defined according to the revised National Cholesterol Education Program definition that includes three or more of the following criteria: waist circumference $>90 \mathrm{~cm}$ in men or $>80 \mathrm{~cm}$ in women by the WHO Asia Pacific abdominal obesity criteria; serum triacylglycerol $\geq 3.9 \mathrm{mmol} / \mathrm{l}$ or medication use; HDL-cholesterol $<1.0 \mathrm{mmol} / 1$ in men or $<1.3 \mathrm{mmol} / \mathrm{l}$ in women; $\mathrm{BP} \geq 130 / 85 \mathrm{mmHg}$ or use of antihypertensive medication; or serum fasting glucose $\geq 5.6 \mathrm{mmol} / \mathrm{l}$ or use of glucose-lowering medication [24, 25].

Statistical analysis To minimise potential confounding, we performed propensity score-matched analyses based on the one-to-four nearest-neighbour matching method (Greedy method) using a multivariable logistic regression model. In the propensity score model, presence of ketonuria was the dependent variable and age, sex, BMI, $\mathrm{HbA}_{1 \mathrm{c}}$, post-load $1 \mathrm{~h}$ and $2 \mathrm{~h}$ glucose, and family history of diabetes were included as covariates, yielding 185 participants with, and 740 participants without, ketonuria.

Data are presented as mean \pm SD for continuous variables or frequencies for categorical variables. Group differences were tested using the unpaired Student's $t$ test for continuous variables and the $\chi^{2}$ test for categorical variables. Comparisons of ketonuria status and serum $\beta \mathrm{HB}$ levels were calculated using the Jonckheere-Terpstra trend test. Cumulative diabetes incidence was assessed by KaplanMeier survival functions, and the associated probability was tested using the logrank test. Cox proportional hazards analysis was performed to estimate HRs and $95 \%$ CIs, to test the independent association between ketonuria and incident diabetes. In multivariate analyses, age, sex, obesity (BMI $\geq 25 \mathrm{~kg}$ / $\mathrm{m}^{2}$ as a categorical value), post-load $1 \mathrm{~h}$ and $2 \mathrm{~h}$ glucose, postload $1 \mathrm{~h}$ and $2 \mathrm{~h}$ insulin concentrations, insulin resistance 
(HOMA-IR > 2.5 as a categorical value), eGFR, triacylglycerols, HDL-cholesterol, family history of diabetes, hypertension, smoking, alcohol consumption, exercise status and carbohydrate intake ( $\mathrm{g}$ ) were used as covariates. A $p$ value $<0.05$ was considered statistically significant. Statistical analyses were performed using IBM SPSS Statistics version 23.0 for Windows (IBM, Armonk, NY, USA).

\section{Results}

Clinical and laboratory characteristics of participants at baseline The baseline characteristics of the 8703 participants of the whole cohort by presence of ketonuria are shown in ESM Table 1 . The mean age of all participants ( $53 \%$ women) was $52 \pm 9$ years and their mean BMI was $24.5 \pm 3.1 \mathrm{~kg} / \mathrm{m}^{2}$. In the
Table 1 Baseline characteristics of the study participants according to the presence or absence of ketonuria after propensity score matching $(n=925)$

\begin{tabular}{|c|c|c|c|}
\hline Characteristic & No ketonuria $(n=740)$ & Ketonuria $(n=185)$ & $p$ value \\
\hline Age, years ${ }^{\mathrm{a}}$ & $51.6 \pm 9.1$ & $51.2 \pm 8.9$ & 0.616 \\
\hline Female $^{\mathrm{a}}$ & $354(47.8)$ & $87(47.0)$ & 0.869 \\
\hline Body weight, $\mathrm{kg}$ & $61.5 \pm 10.0$ & $61.5 \pm 10.2$ & 0.984 \\
\hline BMI, $\mathrm{kg} / \mathrm{m}^{2 \mathrm{a}}$ & $23.8 \pm 3.0$ & $23.7 \pm 3.2$ & 0.608 \\
\hline Obesity & $258(34.9)$ & $57(30.8)$ & 0.340 \\
\hline Waist circumference, $\mathrm{cm}$ & $80.7 \pm 8.9$ & $79.1 \pm 9.0$ & 0.030 \\
\hline Fat mass, $\mathrm{kg}$ & $15.8 \pm 5.3$ & $15.6 \pm 5.8$ & 0.683 \\
\hline Body fat, $\%$ & $25.5 \pm 7.1$ & $25.1 \pm 7.8$ & 0.635 \\
\hline Fat-free mass, $\mathrm{kg}$ & $46.0 \pm 8.3$ & $46.1 \pm 8.4$ & 0.900 \\
\hline Hypertension & $229(30.9)$ & $54(29.2)$ & 0.721 \\
\hline Systolic BP, mmHg & $120.7 \pm 18.8$ & $120.0 \pm 19.0$ & 0.639 \\
\hline Diastolic BP, mmHg & $79.8 \pm 11.8$ & $80.6 \pm 12.2$ & 0.420 \\
\hline Family history of diabetes ${ }^{\mathrm{a}}$ & $55(7.4)$ & $12(6.5)$ & 0.752 \\
\hline Smoking, never/past/current, $\%$ & $55 / 20 / 25$ & $58 / 15 / 27$ & 0.274 \\
\hline Alcohol $<1 / 1-<5 / \geq 5$ drinks/day, $\%$ & $75 / 19 / 6$ & $74 / 20 / 6$ & 0.834 \\
\hline Exercise none/ $\geq$ once weekly, $\%$ & $74 / 26$ & $68 / 32$ & 0.059 \\
\hline Metabolic syndrome & $206(27.8)$ & $30(16.2)$ & 0.001 \\
\hline $\mathrm{HbA}_{1 \mathrm{c}}, \mathrm{mmol} / \mathrm{mol}^{\mathrm{a}}$ & $37.0 \pm 2.0$ & $37.0 \pm 2.0$ & 0.610 \\
\hline Fasting glucose, mmol/1 & $4.7 \pm 0.5$ & $4.6 \pm 0.5$ & 0.065 \\
\hline $1 \mathrm{~h}$ glucose, $\mathrm{mmol} / \mathrm{l}^{\mathrm{a}}$ & $8.8 \pm 2.4$ & $8.8 \pm 2.4$ & 0.917 \\
\hline $2 \mathrm{~h}$ glucose, $\mathrm{mmol} / \mathrm{l}^{\mathrm{a}}$ & $6.7 \pm 1.8$ & $6.7 \pm 1.9$ & 0.923 \\
\hline Fasting insulin, pmol/1 & $7.3 \pm 4.3$ & $6.2 \pm 2.9$ & 0.002 \\
\hline $1 \mathrm{~h}$ insulin, $\mathrm{pmol} / 1$ & $224.3 \pm 217.4$ & $207.0 \pm 175.7$ & 0.299 \\
\hline $2 \mathrm{~h}$ insulin, $\mathrm{pmol} / 1$ & $207.7 \pm 213.9$ & $173.6 \pm 172.9$ & 0.044 \\
\hline HOMA-IR & $1.54 \pm 0.95$ & $1.30 \pm 0.66$ & 0.002 \\
\hline IGI & $9.9 \pm 15.8$ & $11.2 \pm 23.2$ & 0.421 \\
\hline eGFR, $\mathrm{ml} \mathrm{min} \min ^{-1} 1.73 \mathrm{~m}^{-2}$ & $86.0 \pm 17.8$ & $83.1 \pm 19.5$ & 0.053 \\
\hline Total cholesterol, mmol/1 & $4.9 \pm 0.9$ & $5.0 \pm 0.9$ & 0.056 \\
\hline Triacylglycerol, mmol/1 & $1.8 \pm 1.1$ & $1.4 \pm 1.0$ & $<0.001$ \\
\hline HDL-cholesterol, mmol/1 & $1.2 \pm 0.3$ & $1.3 \pm 0.3$ & $<0.001$ \\
\hline LDL-cholesterol, mmol/1 & $2.9 \pm 0.9$ & $3.1 \pm 0.9$ & 0.004 \\
\hline Total energy intake, $\mathrm{kJ}^{\mathrm{b}}$ & $8129.1 \pm 2795.3$ & $7638.7 \pm 3093.6$ & 0.040 \\
\hline Carbohydrate, $\mathrm{g}$ & $344.2 \pm 116.3$ & $319.8 \pm 101.6$ & 0.010 \\
\hline Protein, $g$ & $66.9 \pm 26.9$ & $64.1 \pm 43.0$ & 0.270 \\
\hline Fat, $g$ & $33.2 \pm 19.2$ & $32.3 \pm 30.5$ & 0.616 \\
\hline Carbohydrate, $\%$ & $71.5 \pm 7.5$ & $71.2 \pm 8.8$ & 0.669 \\
\hline Protein, $\%$ & $13.7 \pm 2.3$ & $13.8 \pm 2.8$ & 0.674 \\
\hline Fat, \% & $14.8 \pm 5.6$ & $15.0 \pm 6.4$ & 0.689 \\
\hline
\end{tabular}

Data are presented as mean $\pm \mathrm{SD}$ or $n(\%)$

${ }^{\text {a }}$ Variable included in propensity score matching

${ }^{\mathrm{b}}$ Owing to missing dietary information, 895 individuals (714 no ketonuria/181 ketonuria) were analysed 
185 participants with ketonuria, the distribution of ketonuria was $76.4 \%$ (trace), $21.0 \%(1+)$ and $2.6 \%(\geq 2+)$. Compared with participants without ketonuria, those with ketonuria were less obese, had less fat mass and were less likely to have the metabolic syndrome, but had similar fat-free mass. Levels of $\mathrm{HbA}_{1 \mathrm{c}}$, fasting and post-load $1 \mathrm{~h}$ insulin, HOMA-IR and triacylglycerols were significantly lower, while levels of postload $1 \mathrm{~h}$ and $2 \mathrm{~h}$ glucose and HDL-cholesterol were higher in participants with ketonuria compared with those without ketonuria; fasting glucose concentrations were similar in both groups. Individuals with fasting ketonuria consumed slightly less total energy and carbohydrate compared with those without ketonuria, but the percentage of total energy from carbohydrate was not significantly different between the two groups (ESM Table 1). As different baseline characteristics may introduce confounding in the analysis, we used propensity score matching on age, sex, BMI, $\mathrm{HbA}_{1 \mathrm{c}}$, post-load $1 \mathrm{~h}$ and $2 \mathrm{~h}$ glucose, and family history of diabetes, in a 1:4 ratio. Table 1 shows that the baseline clinical and laboratory characteristics were comparable between the propensity scorematched groups, with the exception of fasting and post-load $2 \mathrm{~h}$ insulin, triacylglycerol concentrations and total energy and carbohydrate intake, which were lower, and HDL- and LDLcholesterol, which were higher, in the ketonuria compared with the no-ketonuria group.

\section{Association between ketonuria and incident diabetes $\mathrm{Of}$ the} 925 participants in the propensity score-matched cohort, 190 (20.5\%) developed diabetes during the 12 year follow-up period, a crude incidence rate of $1.7 \%$ per year. Of these 925 participants, $165(22.3 \%)$ without ketonuria and $25(13.5 \%)$ with ketonuria developed diabetes. In the whole cohort, $1450(17.0 \%)$ participants without ketonuria and $30(15.4 \%)$ with ketonuria developed diabetes. As shown in Fig. 1, participants with ketonuria had a significantly lower cumulative incidence of diabetes compared with those without ketonuria ( $p=0.024$ by logrank test); by Cox proportional hazards analysis, the relative risk reduction was 0.64 (95\% CI 0.42, 0.98; $p=0.040)$ after adjustment for age, sex and obesity (model 1, Table 2). Also adjusting for post-load $2 \mathrm{~h}$ glucose concentrations, postload $1 \mathrm{~h}$ and $2 \mathrm{~h}$ insulin concentrations, HOMA-IR, triacylglycerols, HDL-cholesterol and eGFR (model 2, Table 2) did not change the association of ketonuria with incident diabetes, which was maintained at the same strength after further adjustment for clinical variables including family history of diabetes, hypertension, smoking, alcohol consumption and exercise status (model 3, Table 2; Fig. 2). After additional adjustment for carbohydrate intake, the association between fasting ketonuria and incident diabetes remained statistically significant (HR 0.63 ; 95\% CI 0.41 , $0.97 ; p=0.037)$ (model 4, Table 2).

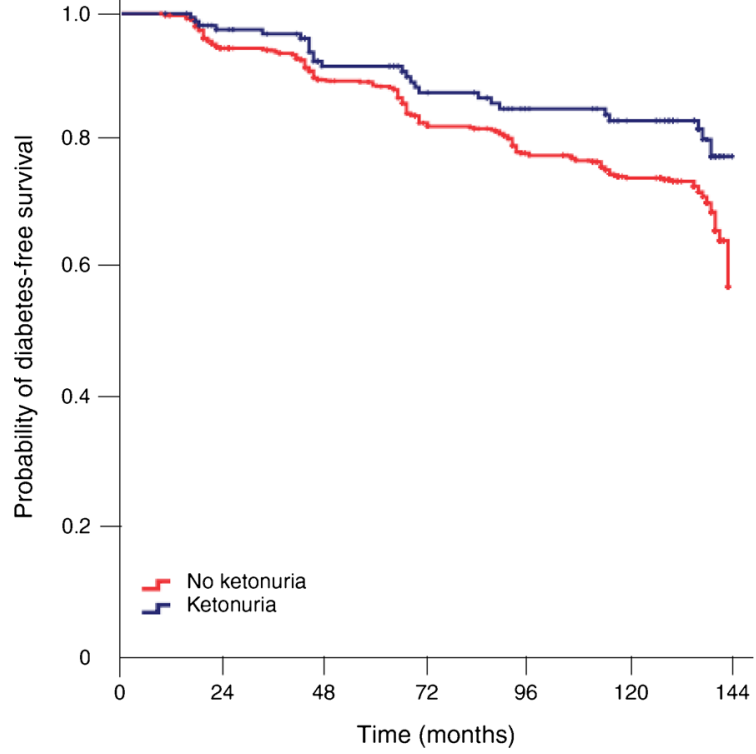

Fig. 1 Twelve year diabetes-free survival according to baseline ketonuria; $p=0.024$ by logrank test

Analysis of the whole cohort $(n=8703)$ yielded very similar results, i.e. an inverse association between ketonuria and incident diabetes, with an HR of 0.66 (95\% CI $0.45,0.96)$ after adjusting for the same set of variables as used in the propensity score-matched groups (ESM Table 2, ESM Table 3). Of note, in this full model most classical factors associated with diabetes (except for sex, drinking habits and eGFR) were statistically significant predictors of its incidence (ESM Table 3).

Trends in metabolic variables during 12 years by ketonuria status The longitudinal changes in metabolic variables (body composition, glucose, HOMA-IR and IGI) were analysed by presence of ketonuria in the whole cohort and in the propensity

Table 2 Association of urinary ketones with the incidence of diabetes in Cox models in the propensity score-matched sample $(n=925)$

\begin{tabular}{llll}
\hline Cox model & HR & $95 \%$ CI & $p$ value \\
\hline Model 1 & 0.64 & $0.42,0.98$ & 0.040 \\
Model 2 & 0.64 & $0.41,0.98$ & 0.040 \\
Model 3 & 0.64 & $0.42,0.99$ & 0.044 \\
Model 4 $^{\text {a }}$ & 0.63 & $0.41,0.97$ & 0.037 \\
\hline
\end{tabular}

Model 1, adjusted for age, sex and BMI $\geq 25 \mathrm{~kg} / \mathrm{m}^{2}$

Model 2, model 1 plus post-load $1 \mathrm{~h}$ and $2 \mathrm{~h}$ glucose concentrations, postload $1 \mathrm{~h}$ and $2 \mathrm{~h}$ insulin concentrations, HOMA-IR $>2.5$, triacylglycerols, HDL-cholesterol and eGFR

Model 3, model 2 plus family history of diabetes, hypertension, smoking, alcohol and exercise status

Model 4, model 3 plus carbohydrate intake (g)

${ }^{a}$ Owing to missing dietary information, 895 individuals were analysed 


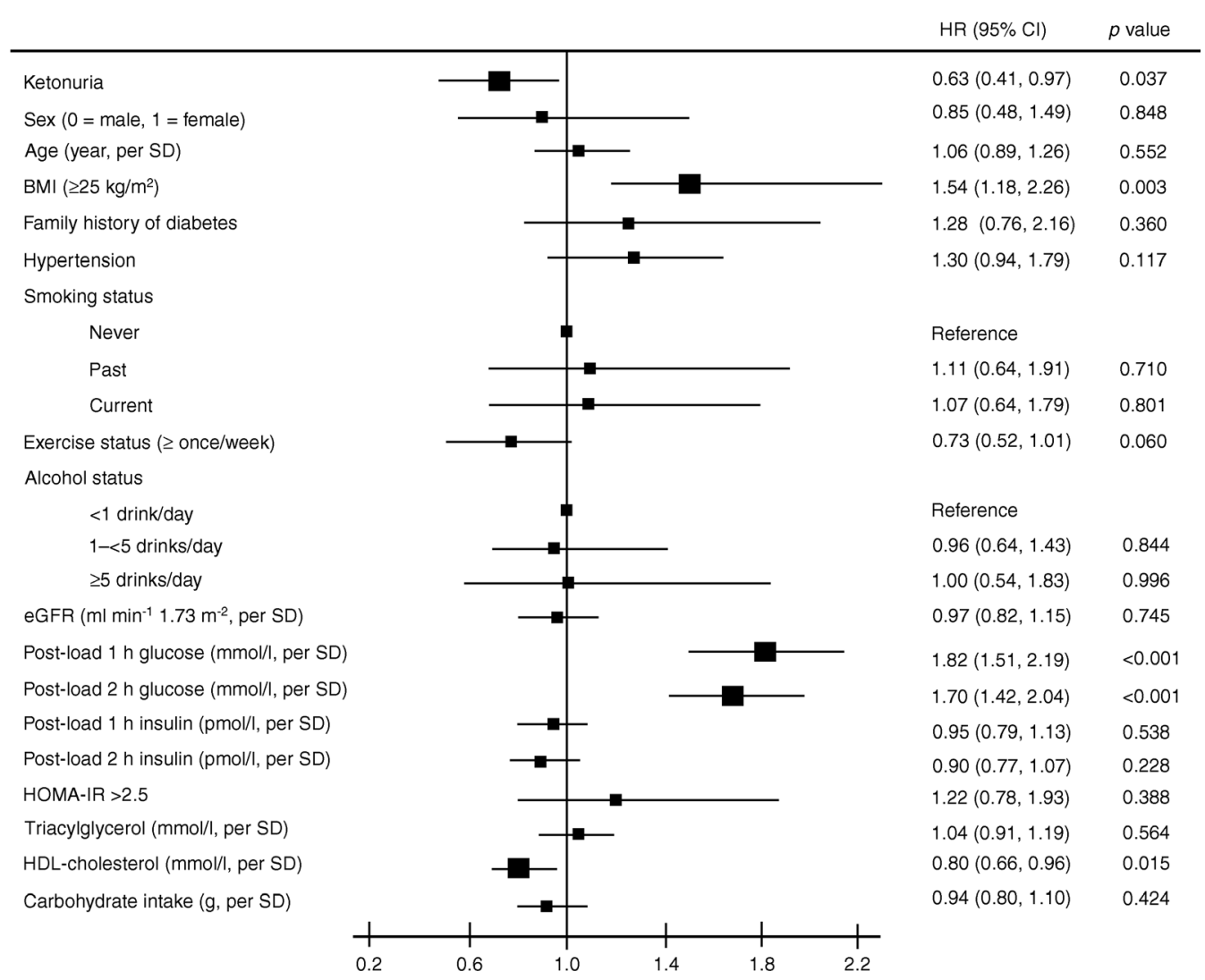

Fig. 2 Multivariate-adjusted Cox regression analysis for incident diabetes by ketonuria status in the propensity score-matched sample $(n=925)$

score-matched subcohort (Fig. 3; ESM Fig. 2). In the whole cohort, fasting and post-load $2 \mathrm{~h}$ glucose levels and HOMA-IR went upwards to a similar extent in the two groups, while BMI, fat mass and per cent body fat remained lower in the participants with ketonuria compared with those without ketonuria (ESM Fig. 2). In the propensity score-matched cohort, no significant differences were observed in body weight and composition between groups over time (Fig. 3). Fasting glucose levels increased similarly between the two groups, whereas post-load $1 \mathrm{~h}$ and $2 \mathrm{~h}$ glucose, which were superimposable at baseline, were maintained at lower levels in the ketonuria group compared with the no-ketonuria group. Whereas HOMA-IR showed a gradual increase without significant difference between the groups, participants with ketonuria had a higher IGI.

\section{Relationship between urinary ketones and serum $\beta \mathrm{HB}$ level} The distribution of urinary ketones in 441 individuals with type 2 diabetes treated with SGLT2 inhibitors is shown in ESM Fig. 3. The majority $(n=275,62.4 \%)$ were negative for strip-based ketonuria. Individuals with trace, $1+$ and $\geq 2+$ ketonuria comprised $23.8 \%, 9.3 \%$ and $4.5 \%$, respectively. As shown in ESM Fig. 4, serum $\beta$ HB levels gradually increased in individuals with trace, $1+$ and $\geq 2+$ ketonuria (mean serum $\beta$ HB levels: none, $0.13 \pm 0.09 \mathrm{mmol} / \mathrm{l}$; trace, $0.29 \pm$ $0.29 \mathrm{mmol} / 1 ; 1+, 0.57 \pm 0.49 \mathrm{mmol} / 1 ; \geq 2+, 2.27 \pm$ $1.70 \mathrm{mmol} / \mathrm{l} ; p$ for trend $<0.001$ ).

\section{Discussion}

The main finding of the study was that ketonuria, as detected by clinical-grade strips in the morning after an overnight fast, was present in a small percentage $(2.2 \%)$ of a non-diabetic population-based cohort, and was associated with a reduced rate of incident diabetes during 12 years of follow-up. The relative diabetes risk reduction was consistent in both size and statistical significance across the whole cohort and a propensity score-matched subcohort, and resisted multivariate adjustment in both datasets. In a full multivariate model including the expected diabetes predictors (age, obesity, familial diabetes, hypertension, insulin resistance as HOMA-IR, serum lipids and plasma glucose levels), the presence of ketonuria was still an independent inverse predictor of incident diabetes (ESM Table 3). In the whole cohort, ketonuric individuals were leaner, with less fat mass but similar fat-free mass, had a better serum lipid profile and lower insulin levels but higher post-OGTT glucose levels (ESM Table 1). A finer profile of the ketonuric phenotype emerges from the propensity score-matched subcohort, consisting of just lower insulin levels (both fasting and post-OGTT) and more favourable serum lipid levels (lower triacylglycerols and higher HDLcholesterol, with marginally higher LDL-cholesterol), or, in the aggregate, a lower prevalence of the metabolic syndrome. Importantly, at the biennial visits the propensity score- 
a

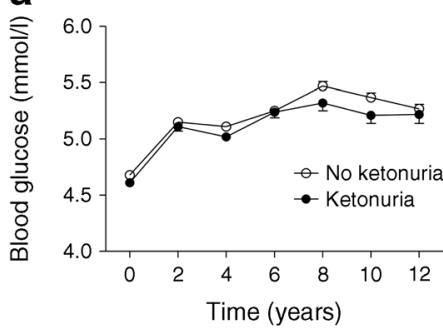

b
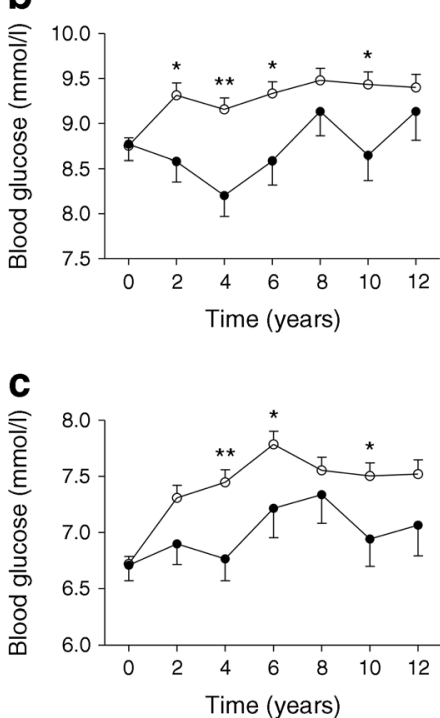

d

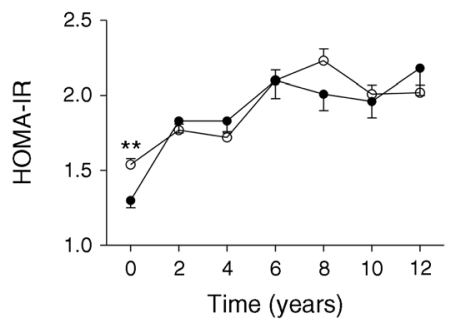

e

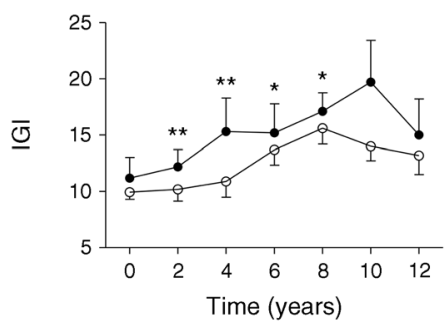

f

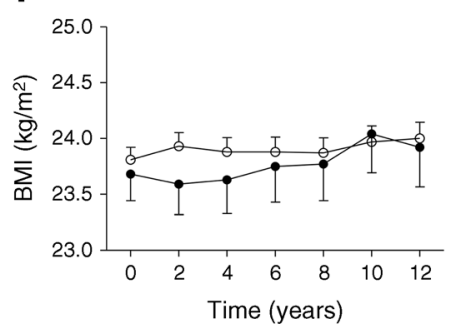

g

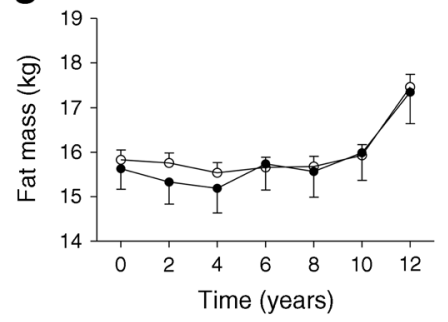

h

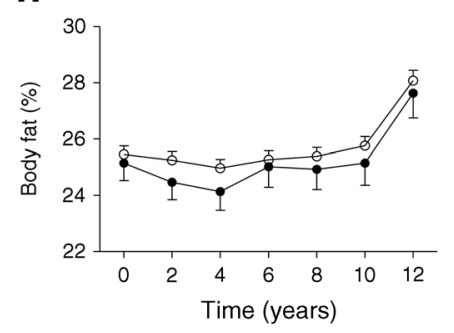

i

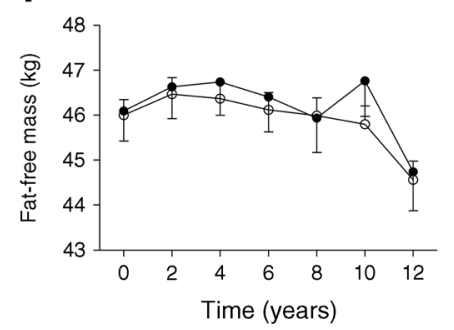

Fig. 3 Longitudinal changes of glycometabolic variables according to presence of ketonuria in the propensity score-matched cohort: (a) fasting glucose, (b) post-load $1 \mathrm{~h}$ glucose, (c) post-load $2 \mathrm{~h}$ glucose, (d) HOMA-
IR, (e) IGI, (f) BMI, (g) fat mass, (h) body fat per cent, (i) fat-free mass. Plots are mean \pm SEM. $* p<0.05$, ** $p<0.01$ between two groups

in individuals with spontaneous ketonuria compared with those without ketonuria. Previously, prolonged or intermittent fasting was associated with reductions in body weight, fasting glucose and insulin levels and insulin resistance [31]. In addition, longer nocturnal fasting intervals could ameliorate systemic inflammation and positively influence other lifestyle behaviours such as sleep, which could subsequently reduce risks of chronic diseases [32, 33]. Prolonged fasting periods could alter gut permeability and composition of gut microbiota, which may lead to improvement in systemic inflammation and metabolic variables [34]. Therefore, the role of intermittent fasting and low-carbohydrate intake on the presence of spontaneous ketonuria needs to be investigated in future controlled studies.

Of relevance is that most ketogenic, low-carbohydrate diets implement a reduced energy intake and, consequently, result in some weight loss. For example, a recent non-randomised trial of a type 2 diabetes care model involving adherence to a supervised very-low-carbohydrate intake ( $<30 \mathrm{~g} /$ day) led to a marked improvement in glycaemic control at 1 year [29]. Individually monitored blood ketone levels doubled over this period, but body weight decreased by an average of $14 \mathrm{~kg}$ vs $1 \mathrm{~kg}$ in a usual care group. Thus, the relative contribution of 
hyperketonaemia and weight loss to the observed changes in metabolic status cannot be dissected out with this approach. By contrast, in our ketonuric participants, body weight and composition were remarkably stable over a long period of time, thereby suggesting a weight-independent link between relative hyperketonaemia and evolution of glucose tolerance.

There are several potential mechanisms for the pleiotropic role of ketone bodies in glucose metabolism. First, in the process of formation of ketone bodies, nuclear receptor peroxisome proliferator-activated receptor, alpha (PPAR $\alpha)$ and one of its downstream targets, fibroblast growth factor 21 (FGF21), are strongly induced, and Hmgcs 2 transcription is increased in the liver [35-38]. HMGCS2 may also induce $F g f 21$ gene expression [39]. In turn, PPAR $\alpha$ and FGF21 play critical roles in glucose metabolism and may have preventive potential for diabetes [40-42]. Conversely, impaired ketogenesis in human non-alcoholic fatty liver disease/non-alcoholic steatohepatitis directs acetyl-CoA to activate tricarboxylic acid flux, thereby increasing reactive oxygen species-mediated injury, de novo synthesis of cytotoxic lipid species, and limited NADH re-oxidation [43]. Ketone bodies possess signalling activities and may be directly involved in insulin action. In hepatocytes, $\beta \mathrm{HB}$ activates AMP kinase and peroxisome proliferator-activated receptor, gamma, coactivator 1 , alpha (PGC-1 $\alpha$ ), which could relate to increased liver insulin sensitivity $[44,45]$. As an endogenous histone deacetylase inhibitor, $\beta \mathrm{HB}$ regulates the expression of gluconeogenic genes [7, $46,47]$. In rodents, increased blood $\beta$ HB stimulates brown adipose tissue, lowers visceral and omental adipocyte size and improves insulin resistance [48, 49]. In athletes during exercise, ketosis induced by the administration of a ketone ester enhanced metabolic flexibility, reducing glycolysis and increasing intramuscular fat oxidation [50]. Through $\mathrm{G}$ protein-coupled receptors, $\beta \mathrm{HB}$ was reported to suppress sympathetic nervous system activity [51]. In addition, liverderived $\beta \mathrm{HB}$ [52] or astrocyte-derived ketogenesis within the ventromedial hypothalamus may play a role in appetite regulation [53]. With regard to effects on pancreatic beta cells, it has long been known that ketone bodies can stimulate insulin secretion in experimental animals and humans [54-56]. Finally, the activity of $\beta \mathrm{HB}$ may reflect its potential in the regulation of inflammation and oxidative stress [57-60]. Clearly, the target organs, circumstances, time course and quantitative relevance of these mechanisms to metabolic homeostasis remain to be assessed in clinical studies.

The present study has several limitations. First, ketonuria serves as a semi-quantitative indicator of ketosis by detecting acetoacetate in the urine [61]. Second, blood $\beta$ HB levels were not available in the study cohort, although the ancillary study in ESM Fig. 4 does provide a robust relationship between urine and blood ketones. Third, we assessed the dietary information on total energy and carbohydrate intake but could not assess specific types in carbohydrates, glycaemic index or glycaemic load, which could influence circulating blood glucose levels and glucose metabolism. In addition, blood samples were collected after at least an $8 \mathrm{~h}$ fast, but individual fasting duration, which could impact concentrations of blood and urine ketone bodies, was not available. Future research regarding the role of intermittent fasting and specific carbohydrate intake is necessary to determine the physiological mechanisms by which ketone bodies and metabolic health are associated. Moreover, in this study only baseline data of urinary ketones could be analysed, as longitudinal data had too many missing values. Finally, this study was based on a sample of Korean individuals in a population-based setting, which may limit the ability to generalise our results to other ethnicities or settings.

In conclusion, we show that spontaneous fasting ketonuria is significantly associated with a reduced risk of developing type 2 diabetes, after adjustment for multiple covariates. Spontaneous fasting ketonuria may be a novel signature in the modulation of glucose metabolism and have the potential to prevent diabetes.

Acknowledgements Data in this study were from the KoGES (4851302), National Research Institute of Health, Centers for Disease Control and Prevention, Ministry for Health and Welfare, Republic of Korea.

Data availability All relevant data are available in this article and ESM files.

Funding This research was supported by grants from the National Research Foundation of Korea (NRF) funded by the Ministry of Science and ICT (NRF-2016R1A5A1010764) and from the Korea Healthcare Technology R\&D Project, Ministry of Health and Welfare, Republic of Korea (HI17C0913).

Duality of interest The authors declare that they have no competing interests.

Contribution statement $\mathrm{GK}$ and $\mathrm{Y}-\mathrm{hL}$ conceived and designed the study and performed the analyses. GK, NHC, S-GL and Y-hL acquired the data. GK, EF and Y-hL wrote the first draft of the manuscript. All authors interpreted the data, contributed to the writing of the manuscript and read and approved the final version. Y-hL and NHC are responsible for the integrity of the work as a whole.

Publisher's note Springer Nature remains neutral with regard to jurisdictional claims in published maps and institutional affiliations.

\section{References}

1. Kahn SE (2003) The relative contributions of insulin resistance and beta-cell dysfunction to the pathophysiology of type 2 diabetes. Diabetologia 46(1):3-19. https://doi.org/10.1007/s00125-0021009-0

2. Han CY (2016) Roles of reactive oxygen species on insulin resistance in adipose tissue. Diabetes Metab J 40(4):272-279. https:// doi.org/10.4093/dmj.2016.40.4.272

3. McGarry JD, Foster DW (1980) Regulation of hepatic fatty acid oxidation and ketone body production. Annu Rev Biochem 49(1): 395-420. https://doi.org/10.1146/annurev.bi.49.070180.002143 
4. Cotter DG, Ercal B, Huang X et al (2014) Ketogenesis prevents diet-induced fatty liver injury and hyperglycemia. J Clin Invest 124(12):5175-5190. https://doi.org/10.1172/JCI76388

5. Beisswenger BG, Delucia EM, Lapoint N, Sanford RJ, Beisswenger PJ (2005) Ketosis leads to increased methylglyoxal production on the Atkins diet. Ann N Y Acad Sci 1043(1):201210. https://doi.org/10.1196/annals.1333.025

6. Cotter DG, Schugar RC, Crawford PA (2013) Ketone body metabolism and cardiovascular disease. Am J Physiol Heart Circ Physiol 304(8):H1060-H1076. https://doi.org/10.1152/ajpheart.00646. 2012

7. Newman JC, Verdin E (2014) Ketone bodies as signaling metabolites. Trends Endocrinol Metab 25(1):42-52. https://doi.org/10. 1016/j.tem.2013.09.002

8. Ferrannini E, Mark M, Mayoux E (2016) CV protection in the EMPA-REG outcome trial: a 'thrifty substrate' hypothesis. Diabetes Care 39(7):1108-1114. https://doi.org/10.2337/dc160330

9. Ferrannini E, Baldi S, Frascerra $S$ et al (2016) Shift to fatty substrate utilization in response to sodium-glucose cotransporter 2 inhibition in subjects without diabetes and patients with type 2 siabetes. Diabetes 65(5):1190-1195. https://doi.org/10.2337/db15-1356

10. Joo NS, Lee DJ, Kim KM et al (2010) Ketonuria after fasting may be related to the metabolic superiority. J Korean Med Sci 25(12): 1771-1776. https://doi.org/10.3346/jkms.2010.25.12.1771

11. Ferrannini E (2017) Sodium-glucose co-transporters and their inhibition: clinical physiology. Cell Metab 26(1):27-38. https://doi.org/ 10.1016/j.cmet.2017.04.011

12. Kim Y, Han BG (2017) Cohort profile: the Korean Genome and Epidemiology Study (KoGES) Consortium. Int J Epidemiol 46(4): 1350. https://doi.org/10.1093/ije/dyx 105

13. Kim G, Lee YH, Jeon JY et al (2017) Increase in resting heart rate over 2 years predicts incidence of diabetes: a 10-year prospective study. Diabetes Metab 43(1):25-32. https://doi.org/10.1016/j. diabet.2016.09.002

14. Ahn Y, Park SJ, Kwack HK, Kim MK, Ko KP, Kim SS (2013) Rice-eating pattern and the risk of metabolic syndrome especially waist circumference in Korean Genome and Epidemiology Study (KoGES). BMC Public Health 13(1):61. https://doi.org/10.1186/ 1471-2458-13-61

15. Cho NH, Cho AK, Kim HK et al (2017) Carbohydrate composition associated with the 2-year incidence of metabolic syndrome in Korean adults. Clin Nutr Res 6(2):122-129. https://doi.org/10. 7762/cnr.2017.6.2.122

16. Son JW, Lee SS, Kim SR et al (2017) Low muscle mass and risk of type 2 diabetes in middle-aged and older adults: findings from the KoGES. Diabetologia 60(5):865-872. https://doi.org/10.1007/ s00125-016-4196-9

17. Ahn Y, Kwon E, Shim JE et al (2007) Validation and reproducibility of food frequency questionnaire for Korean genome epidemiologic study. Eur J Clin Nutr 61(12):1435-1441. https://doi.org/10.1038/ sj.ejen. 1602657

18. Ahn Y, Lee JE, Paik HY, Lee HK, Jo I, Kimm K (2003) Development of a semi-quantitative food frequency questionnaire based on dietary data from the Korea National Health and Nutrition Examination Survey. Nutr Sci 6:173-184

19. World Health Organization. Regional Office for the Western Pacific (2000) The Asian-Pacific perspective: redefining obesity and its treatment. Health Communications Australia, Sydney

20. Friedewald WT, Levy RI, Fredrickson DS (1972) Estimation of the concentration of low-density lipoprotein cholesterol in plasma, without use of the preparative ultracentrifuge. Clin Chem 18(6): 499-502

21. Matthews DR, Hosker JP, Rudenski AS, Naylor BA, Treacher DF, Turner RC (1985) Homeostasis model assessment: insulin resistance and beta-cell function from fasting plasma glucose and insulin concentrations in man. Diabetologia 28:412-419

22. Tura A, Kautzky-Willer A, Pacini G (2006) Insulinogenic indices from insulin and C-peptide: comparison of beta-cell function from OGTT and IVGTT. Diabetes Res Clin Pract 72:298-301

23. American Diabetes Association (2004) Diagnosis and classification of diabetes mellitus. Diabetes Care 27(suppl 1):s5-s10

24. Grundy SM, Cleeman JI, Daniels SR et al (2005) Diagnosis and management of the metabolic syndrome: an American Heart Association/National Heart, Lung, and Blood Institute scientific statement. Circulation 112(17):2735-2752. https://doi.org/10. 1161/CIRCULATIONAHA.105.169404

25. Lim S, Kim JH, Yoon JW et al (2010) Sarcopenic obesity: prevalence and association with metabolic syndrome in the Korean Longitudinal Study on Health and Aging (KLoSHA). Diabetes Care 33(7):1652-1654. https://doi.org/10.2337/dc10-0107

26. Musa-Veloso K, Likhodii SS, Cunnane SC (2002) Breath acetone is a reliable indicator of ketosis in adults consuming ketogenic meals. Am J Clin Nutr 76(1):65-70. https://doi.org/10.1093/ajen/76.1.65

27. Yancy WS Jr, Olsen MK, Guyton JR, Bakst RP, Westman EC (2004) A low-carbohydrate, ketogenic diet versus a low-fat diet to treat obesity and hyperlipidemia: a randomized, controlled trial. Ann Intern Med 140(10):769-777. https://doi.org/10.7326/00034819-140-10-200405180-00006

28. Perez-Guisado J (2008) Ketogenic diets: additional benefits to the weight loss and unfounded secondary effects. Arch Latinoam Nutr 58:323-329 [article in Spanish]

29. Tendler D, Lin S, Yancy WS Jr et al (2007) The effect of a lowcarbohydrate, ketogenic diet on nonalcoholic fatty liver disease: a pilot study. Dig Dis Sci 52(2):589-593. https://doi.org/10.1007/ s10620-006-9433-5

30. Horne BD, Muhlestein JB, Anderson JL (2015) Health effects of intermittent fasting: hormesis or harm? A systematic review. Am J Clin Nutr 102(2):464-470. https://doi.org/10.3945/ajen.115. 109553

31. Patterson RE, Laughlin GA, LaCroix AZ et al (2015) Intermittent fasting and human metabolic health. J Acad Nutr Diet 115(8):12031212. https://doi.org/10.1016/j.jand.2015.02.018

32. Marinac CR, Sears DD, Natarajan L, Gallo LC, Breen CI, Patterson RE (2015) Frequency and circadian timing of eating may influence biomarkers of inflammation and insulin resistance associated with breast cancer risk. PLoS One 10(8):e0136240. https://doi.org/10. 1371/journal.pone. 0136240

33. Gallant A, Drapeau V, Allison KC et al (2014) Night eating behavior and metabolic heath in mothers and fathers enrolled in the QUALITY cohort study. Eat Behav 15(2):186-191. https://doi. org/10.1016/j.eatbeh.2014.01.002

34. Tilg H, Kaser A (2011) Gut microbiome, obesity, and metabolic dysfunction. J Clin Invest 121(6):2126-2132. https://doi.org/10. 1172/JCI58109

35. Rodriguez JC, Gil-Gomez G, Hegardt FG, Haro D (1994) Peroxisome proliferator-activated receptor mediates induction of the mitochondrial 3-hydroxy-3-methylglutaryl-CoA synthase gene by fatty acids. J Biol Chem 269(29):18767-18772

36. Badman MK, Pissios P, Kennedy AR, Koukos G, Flier JS, MaratosFlier E (2007) Hepatic fibroblast growth factor 21 is regulated by $\operatorname{PPAR} \alpha$ and is a key mediator of hepatic lipid metabolism in ketotic states. Cell Metab 5(6):426-437. https://doi.org/10.1016/j.cmet. 2007.05.002

37. Kim JH, Lee M, Kim SH et al (2018) Sodium-glucose cotransporter 2 inhibitors regulate ketone body metabolism via inter-organ crosstalk. Diabetes Obes Metab. https://doi.org/10. 1111/dom. 13577

38. Bae KH, Kim JG, Park KG (2014) Transcriptional regulation of fibroblast growth factor 21 expression. Endocrinol Metab (Seoul) 29(2):105-111. https://doi.org/10.3803/EnM.2014.29.2.105 
39. Vila-Brau A, De Sousa-Coelho AL, Mayordomo C, Haro D, Marrero PF (2011) Human HMGCS2 regulates mitochondrial fatty acid oxidation and FGF21 expression in HepG2 cell line. J Biol Chem 286(23):20423-20430. https://doi.org/10.1074/jbc.M111. 235044

40. Degirolamo C, Sabba C, Moschetta A (2016) Therapeutic potential of the endocrine fibroblast growth factors FGF19, FGF21 and FGF23. Nat Rev Drug Discov 15(1):51-69. https://doi.org/10. 1038/nrd.2015.9

41. Kim KH, Lee MS (2014) FGF21 as a stress hormone: the roles of FGF21 in stress adaptation and the treatment of metabolic diseases. Diabetes Metab J 38(4):245-251. https://doi.org/10.4093/dmj. 2014.38.4.245

42. Lee JM (2017) Nuclear receptors resolve endoplasmic reticulum stress to improve hepatic insulin resistance. Diabetes Metab J 41(1):10-19. https://doi.org/10.4093/dmj.2017.41.1.10

43. Satapati S, Sunny NE, Kucejova B et al (2012) Elevated TCA cycle function in the pathology of diet-induced hepatic insulin resistance and fatty liver. J Lipid Res 53(6):1080-1092. https://doi.org/10. 1194/jlr.M023382

44. Bae HR, Kim DH, Park MH et al (2016) $\beta$-Hydroxybutyrate suppresses inflammasome formation by ameliorating endoplasmic reticulum stress via AMPK activation. Oncotarget 7(41):6644466454. https://doi.org/10.18632/oncotarget.12119

45. Gao Z, Yin J, Zhang J et al (2009) Butyrate improves insulin sensitivity and increases energy expenditure in mice. Diabetes 58(7): 1509-1517. https://doi.org/10.2337/db08-1637

46. Mihaylova MM, Vasquez DS, Ravnskjaer K et al (2011) Class IIa histone deacetylases are hormone-activated regulators of FOXO and mammalian glucose homeostasis. Cell 145(4):607-621. https://doi.org/10.1016/j.cell.2011.03.043

47. Knutson SK, Chyla BJ, Amann JM, Bhaskara S, Huppert SS, Hiebert SW (2008) Liver-specific deletion of histone deacetylase 3 disrupts metabolic transcriptional networks. EMBO J 27(7): 1017-1028. https://doi.org/10.1038/emboj.2008.51

48. Veech RL (2013) Ketone esters increase brown fat in mice and overcome insulin resistance in other tissues in the rat. Ann N Y Acad Sci 1302(1):42-48. https://doi.org/10.1111/nyas.12222

49. Holland AM, Kephart WC, Mumford PW et al (2016) Effects of a ketogenic diet on adipose tissue, liver, and serum biomarkers in sedentary rats and rats that exercised via resisted voluntary wheel running. Am J Physiol Regul Integr Comp Physiol 311(2):R337R351. https://doi.org/10.1152/ajpregu.00156.2016
50. Cox PJ, Kirk T, Ashmore T et al (2016) Nutritional ketosis alters fuel preference and thereby endurance performance in athletes. Cell Metab 24(2):256-268. https://doi.org/10.1016/j.cmet.2016.07.010

51. Kimura I, Inoue D, Maeda T et al (2011) Short-chain fatty acids and ketones directly regulate sympathetic nervous system via $G$ proteincoupled receptor 41 (GPR41). Proc Natl Acad Sci U S A 108(19): 8030-8035. https://doi.org/10.1073/pnas.1016088108

52. Laeger T, Metges CC, Kuhla B (2010) Role of beta-hydroxybutyric acid in the central regulation of energy balance. Appetite 54(3): 450-455. https://doi.org/10.1016/j.appet.2010.04.005

53. Le Foll C, Dunn-Meynell AA, Miziorko HM, Levin BE (2014) Regulation of hypothalamic neuronal sensing and food intake by ketone bodies and fatty acids. Diabetes 63(4):1259-1269. https:// doi.org/10.2337/db13-1090

54. Madison LL, Mebane D, Unger RH, Lochner A (1964) The hypoglycemic action of ketones. II. Evidence for a stimulatory feedback of ketones on the pancreatic beta cells. J Clin Invest 43(3):408-415. https://doi.org/10.1172/JCI104925

55. Jenkins DJ, Hunter WM, Goff DV (1970) Ketone bodies and evidence for increased insulin secretion. Nature 227(5256):384-385. https://doi.org/10.1038/227384a0

56. Balasse EO, Ooms HA, Lambilliotte JP (1970) Evidence for a stimulatory effect of ketone bodies on insulin secretion in man. Horm Metab Res 2(06):371-372. https://doi.org/10.1055/s-00281096822

57. Shimazu T, Hirschey MD, Newman J et al (2013) Suppression of oxidative stress by $\beta$-hydroxybutyrate, an endogenous histone deacetylase inhibitor. Science 339(6116):211-214. https://doi.org/ 10.1126/science. 1227166

58. Rahman M, Muhammad S, Khan MA et al (2014) The $\beta$ hydroxybutyrate receptor HCA2 activates a neuroprotective subset of macrophages. Nat Commun 5(1):3944. https://doi.org/10.1038/ ncomms4944

59. Youm YH, Nguyen KY, Grant RW et al (2015) The ketone metabolite $\beta$-hydroxybutyrate blocks NLRP3 inflammasome-mediated inflammatory disease. Nat Med 21(3):263-269. https://doi.org/10. 1038/nm.3804

60. Robinson AM, Williamson DH (1980) Physiological roles of ketone bodies as substrates and signals in mammalian tissues. Physiol Rev 60(1):143-187. https://doi.org/10.1152/physrev.1980.60.1.143

61. Klocker AA, Phelan H, Twigg SM, Craig ME (2013) Blood $\beta$ hydroxybutyrate vs. urine acetoacetate testing for the prevention and management of ketoacidosis in type 1 diabetes: a systematic review. Diabet Med 30(7):818-824. https://doi.org/10.1111/dme.12136 